\title{
Bridging the Sustainability Leadership Chasm: A Case Study of the Sustainability Advantage Program of the NSW Government, Australia
}

\author{
Charmaine Batulan \\ UNSW Business School \\ c.batulan@student.unsw.edu.au
}

\author{
Felix Ter Chian Tan \\ UNSW Business School \\ f.tan@unsw.edu.au
}

\author{
Calvin M.L. Chan \\ Singapore University of Social Sciences \\ calvinchanml@suss.edu.sg
}

\begin{abstract}
Business operations worldwide have significantly impacted the environment, prompting organisations to consider how to align strategy and conduct to advance sustainability targets. Collaboration is critical for sustainability progress, thus organisations are becoming interested in the practices of supply chain partners. To incorporate sustainability across networks, leadership is critical in coordinating activities. Although the effectiveness of leadership for sustainability is widely discussed, there is a lack of empirical field studies on how organisations can develop this leadership capability. This research-inprogress paper presents preliminary findings from an industry level case study of a Government-run initiative. This initiative provides a platform for organisations to collaborate and access resources that supports the development of sustainability leadership capabilities. Preliminary analysis provides insight on the dynamic capabilities organisations must develop to influence its supply chain partners, the technologies used to progress sustainability initiatives and the role that the Government has in promoting collaboration and leadership. Implications to both research and practice, and future work are discussed in conclusion.
\end{abstract}

\section{Introduction}

The concerning rates at which environmental resources are depleting has led organisations to consider the historically overlooked value of sustainable development. The United Nations highlights sustainable development as the ability to meet current needs without exhausting future resources [1]. These sustainability agendas are directly aligned to the United Nations' Sustainable Development Goals (SDGs), which promotes sustainable consumption and production patterns through the mobilisation of all resources [2].There is growing interest on how relationships along the supply chain can be leveraged to enable collaboration to further sustainable development [3, 4]. For a firm to successfully meet the requirements of the SDGS or their Carbon Neutral by 2030 commitment, it is critical they shape the practices of their supply chain partners. However, due to the complexity of interactions and varying levels of maturity amongst suppliers in terms of sustainable practices, leadership is critical in coordinating all activities.

This crucial process of developing leadership capabilities to orchestrate the sustainability of a supply chain is understudied. Leadership drives the performance of supply chains, not only by providing structure to their operations, but also through equipping them with the necessary resources and capabilities to uplift their operational standards [5]. Despite the recognition of leadership's importance for driving change and innovation for sustainability, only $4 \%$ of executive roles specify sustainability as a requirement [6]. Additionally, there is a lack of empirical evidence on how firms, particularly those with immature sustainability models, can develop sustainability leadership and associated capabilities to shape green supply chain practices. Moreover, supply chain sustainability leadership is typically assessed by analysing the practices of leading firms, however it is also important to address sustainability from the perspective of both buyers and sellers. Finally, the enactment of leadership within a broad ecosystem of complex supplier relationships is yet to be explored.

Considering the above, this research attempts to address the gaps by conducting a case study of the New South Wales (NSW) Government Sustainability Advantage (SA) program. The program supports organisations in adopting sustainable practices and nurtures leadership. Although this program involves a network of organisations across a variety of sectors, an in-depth exploration of the infrastructure, construction, transportation, and logistics sector was conducted. To address the lack of empirical validation in existing literature, the research question that this study aims to answer is "How do organisations develop sustainability leadership capabilities to enable supply chains in an industry?"

This paper is structured as follows: the next section presents the background and related prior research on leadership development, with a focus on sustainable supply chains (SSC). The concepts of dynamic 
capabilities are thus introduced and are used to guide the case analysis. The research method is then described before providing the background of the case study. This is followed by the case analysis and discussion regarding how the research question has been addressed. The implications of research and practice are illustrated. In conclusion, future work is discussed.

\section{Background and Prior Research}

\subsection{Sustainability Leadership}

Firms have recognised the importance of collaboration across entire supply chain operations to advance sustainability goals $[3,4,7]$. In practice, the development of SSC is often encapsulated within green supply chain integration $[8,9,10]$. Green supply chain integration addresses the need for a holistic perspective of processes, with an emphasis on the role of buyer-supplier relationships [3, 11, 12]. Firms must collaborate with supply chain partners to enable information sharing, process coordination and strategic alignment for the achievement of sustainability ambitions [9]. As buying firms, they must consider the supply chain in their sustainability strategy, as many sustainability challenges occur due to the differences in standards and policies between firms [4]. In enabling this integration, prior and more systematic reviews on extant supply chain literature highlight the importance of leadership to satisfy the demands of interorganisational collaboration and to orchestrate supply chain activities [13, 14].

Effective SSC initiatives demand leadership, as it is central in fostering collaboration through the legitimisation of governance structures, goals, and the provision of resources [5]. Definitions of leadership typically presume that it refers to one individual in a position of power that aims to influence others to achieve a common goal. However, in defining leadership for sustainability, we cite Tan, Pan and Zuo [13] and Vial [15] who conceptualise it as an organisational capability rather than a managerial or individual concept. Specifically, it explores sustainability leadership as the ability of core firm to influence those within their network to achieve sustainability goals.

Similarly, supply chain literature commonly explores leadership through the perspective of a focal buying firm who demonstrates leadership capability to its partners [14]. This leadership is perceived as an antecedent for strategic decisions and is a key driver for supply chain improvements. Focal buying firms are intermediaries that encourage supply chain partners to engage in dialogue [8]. Within the context of sustainability, this leadership is critical in providing the coordination required to integrate sustainable practices and foster innovation [16, 17, 18].

Despite the widespread recognition of the impact leadership has on environmental performance, sustainability leadership has not been effectively implemented across firms. In fact, according to the United Nations Global Impact, only $48 \%$ of firms are implementing sustainability initiatives into their operations, despite $92 \%$ of CEOs recognising its importance [19]. While the body of literature exploring green leadership and sustainable supply chain management is growing, two main gaps have been identified. Firstly, sustainable leadership literature primarily focuses on the effects of sustainable leadership on sustainable performance and innovation [19, 20, 21, 22], with very few articles exploring how to develop and operationalise sustainability leadership [12]. Secondly, supply chain leadership typically examines the performance of focal firms, however it is imperative to understand leadership and sustainability challenges from the perspective of supply chain partners [9].

\subsection{Program and Platforms}

A platform fosters value creation processes by enabling transactions between two or more constituent user groups [23, 24]. These users include suppliers, intermediaries, and customers who interactions contribute to overall growth [25]. Platforms provide specific rules and practices that govern and enable many activities that these users engage in [26]. Platforms can take on a more significant role in creating value for businesses and their supply chains, specifically in alignment with sustainability targets.

Tan, Pan and Zuo [27] posit that platforms have two key roles, which are reducing the search costs associated with finding transaction partners and reducing the costs that are involved when a transaction occurs. Moreover, platforms thrive because of the network effect where the value of a platform increases as more people use it [28]. In applying this to the context of sustainability and supply chains, a platform will provide organisations with visibility and access to a range of organisations, whilst also attracting more clients and suppliers along the value chain. For example, for organisations seeking to introduce sustainable materials within their organisation will be able to do so more effectively through a platform that governs these transactions. This is critical in advancing progress towards a circular economy, mobilising action from various partner organisations across an entire ecosystem [1]. 
Sedera et al. [29] have identified that there is a growing recognition that technology platforms can have a more salient role in enabling organisational innovation by providing organisations with the capability change resource integration patterns. The introduction of platforms has afforded organisations with limited resources to innovate "in the same fashion as their resourceful counterparts".

There is a growing interest on how these leadership capabilities can be extended for platforms to adopt a more enabling role by leveraging all resources in their possession. Combining these insights with the literature on leadership and SSC, there are two main roles that platforms can adopt in facilitating action towards sustainability development. Firstly, the traditional role of a platform as a governing body that provides rules and structure to facilitate transactions between various parties. This role provides the necessary coordination to drive collection action for sustainable progress, by providing organisations with access to sustainable resources and knowledge. Secondly, platforms can adopt a new role whereby they equip constituent organisations with the necessary resources to develop their own leadership capabilities through streamlining interactions. This is critical in today's landscape as many organisations do not possess sufficient resources to prioritise transformative sustainability initiatives.

\subsection{Theoretical Lens: Dynamic Capabilities}

This study adopts the dynamic capabilities perspective as its theoretical lens. This perspective is derived from the resource-based view (RBV) of the firm to explain how competitive advantage is facilitated by the evolutionary nature of resources and capabilities in accordance with dynamic markets [30]. RBV perceives firms to be composed of various resources, which are valuable and difficult to imitate, thus providing them with a competitive advantage [31]. However, this poses several limitations as this view requires firms to operate in a static and unchanging environment [32]. Dynamic capabilities (DCs) are defined as the capacity of a firm to integrate, reconfigure, and develop resources through organisational and strategic routines to drive competitive advantage [30, 33]. Thus, it provides firms with the ability to identify opportunities within the market but also reconfigure their resources to adapt to changes within the business environment [34].

Given the context of the current study, DCs are important because it provides an understanding of the mechanisms that enable firms to develop organisational leadership capabilities for sustainability [15]. The development of leadership capabilities for sustainability, particularly within the context of complex supply chains, is challenging for many firms. In addition to their pursuit of corporate objectives, such as those of an economic and social nature, successful firms must be able to meet rapidly changing needs and expectations regarding sustainability. To do so, firms must be able to quickly adapt their resource base and processes, which can be achieved through the possession of DCs.

DCs can be categorised into three distinct capabilities, namely sensing, seizing, and reconfiguring [35]. Sensing involves the detection and assessment of opportunities within the external environment. Seizing refers to responding to opportunities adapting and investing in resources to capture value. Finally, reconfiguration is the process of continually recombining resources to stabilisation as shifts in the external environment occur.

Several studies highlight the positive impact that the possession of these DCs have on sustainable performance, specifically supply chains. Chen \& Chang [20] explores the notion of green DCs, which is the ability of a firm to leverage existing resources to identify green opportunities and integrate green knowledge within the company. This study enforced the positive association between green capability and green performance. Moreover, Mousavi, Bossink \& van Vliet [36] contend that dynamic capabilities are essential in reconfiguring relationship-learning activities. That is, to develop sustainable innovation, firms must engage their supply chain and deploy a cluster of DCs for information sharing [37]. Beske [38] provides a theoretical framework on how to build SSC management practices, as well as the identification of dynamic capabilities. It highlights the need for routines to develop sustainable practices, and an understanding of how DCs support supply chain practices must be developed to enhance supply chain performance. Similarly, Reuter et al. [39] explores SSC on global scale, noting that benefits can be realised through integrating sustainability in supply chains through DCs, such as the accumulation of resources and patterns of learning.

While effects of DCs on sustainability is widely explored in literature, many of these studies take a reactive approach, illustrating how firms build capabilities to respond to changes in the external environment. However, studies suggest the potential of DCs to enact market change, specifically the role of capabilities and resources in informing environmental practices [33, 40]. Glavis and Mish [41] are one of the few studies that adopts a proactive approach to influencing sustainability practices within markets. This study highlights that supply chain leadership and the ability to influence partners is dependent on the 
possession of DCs, such as market intelligence, transparency, and education. Such notions are consistent with supply chain literature on the responsibility of a focal firm in improving sustainability practices of partners [8, 14, 42, 43].

Given the context of the current study and its focus on how firms can develop leadership capabilities to create SSC, the DCs perspective is important as it provides a framework for how firms can develop an advantage within the market. In adapting this theoretical lens, this study aims to address two theoretical gaps. Firstly, while Glavis and Mish [41] provide novel insights on how DCs can be used to shape supplier practices, it does so from the perspective of firms where sustainability was deeply ingrained into their organisational practices. As such, it provides limited insight on how firms in their infancy can grow to become sustainability leaders and influence their supply chain. Secondly, dynamic capability literature is typically viewed from the perspective of a single organisation and not at a broader ecosystem level. However, few firms are able to enact sustainability initiatives using their own information, knowledge and resources [10].

\section{Research Method}

The case study research method was adopted to address the research question of how leadership can be operationalised to enable green supply chains [44]. The literature review demonstrated that there is limited empirical evidence for how firms can develop DCs to influence its surrounding markets [40]. As such, the exploratory nature of this study demonstrates the appropriateness of the case study method, as it enables a thorough analysis of emerging processes that are not understood [40, 45]. Moreover, an interpretive approach was adopted to analyse leadership development across various contextual settings and through stakeholder interpretations [46]. Developing the body of literature on leadership and supply chain sustainability at project level required communication with various stakeholders involved in an ecosystem. Observations were made with DCs as the theoretical lens and qualitative data analysis was performed.

The SA Platform was selected as the case to study. As such, the selected companies needed to be platform partners but more specifically, operate within the infrastructure, construction, transportation, and logistics industry. Several criteria were used to inform this decision. Firstly, this industry operates in a dynamic business environment, where stakeholder expectations are continuously changing, thus fulfilling the requirement of the theoretical lens [47]. Secondly, the importance of supply chain sustainability for this industry is a significant concern of consumers and governments [48]. To understand how to effectively develop leadership capabilities for SSC, it is important to examine practices across all levels of sustainability development. Finally, to analyse how DCs manifest in an ecosystem, the selected case needed to focus on a project-level study. We discuss data collection next, following the guidelines of conducting interpretive case studies in this study outlined in Walsham [44] and Klein and Myers [46].

\section{Data Collection and Analysis}

Data was primarily collected from two main sources: 1) interviews with sustainability managers within the NSW government SA program member network; and 2) secondary data from a variety of sources, such as company websites and published materials. The program is a channel for organisations to collaborate and develop ambitious sustainability practices. The objective was to gain an in-depth understanding of the internal and external barriers constraining organisations' commitment and actions to become a sustainability leader and opportunities for the SA Platform to enhance organisations' ability to bridge the chasm to sustainability leadership.

Data collection was conducted virtually and a total of nine preliminary interviews were conducted, with ten additional interviews scheduled. The selected informants manage sustainability operations within their organisations to some extent, and participating organisations operate within the infrastructure, construction, transportation, and logistics industry, based on recommendations from SA Project Officers. The researchers were provided with a list of companies that satisfied the criteria, all of which had varying levels of sustainability maturity. Each interview took approximately 60 minutes, was voice recorded and transcribed for analysis. The involvement of multiple researchers allowed for the triangulation of observations. Data collection was primarily conducted by two authors, with the third author adopting a moderating role during analysis. This was effective in managing and resolving differences.

Table 1 summarises the data collection to date. Information about the interviewees, including their job position, organisation and topics discussed can be found in the table.

\section{Table 1. Summary of Preliminary Interviews}

\begin{tabular}{|c|c|c|c|}
\hline No & $\begin{array}{c}\text { Title of } \\
\text { Interviewee }\end{array}$ & Firms* & Topics Discussed \\
\hline 1 & $\begin{array}{c}\text { NSW Assistant } \\
\text { Sustainability }\end{array}$ & LL & $\begin{array}{c}\text { Background of the } \\
\text { organisation, }\end{array}$ \\
\hline
\end{tabular}




\begin{tabular}{|c|c|c|c|}
\hline & $\begin{array}{c}\text { Manager, } \\
\text { Development }\end{array}$ & & \multirow{9}{*}{$\begin{array}{l}\text { current state of } \\
\text { sustainability } \\
\text { (including } \\
\text { initiatives and } \\
\text { strategy), } \\
\text { sustainability } \\
\text { ambitions, industry } \\
\text { and competitors, } \\
\text { involvement with } \\
\text { SA program, } \\
\text { barriers to } \\
\text { sustainability, } \\
\text { technology usage }\end{array}$} \\
\hline 2 & $\begin{array}{c}\text { Environment and } \\
\text { Sustainability } \\
\text { Manager }\end{array}$ & IF & \\
\hline 3 & $\begin{array}{c}\text { Environmental } \\
\text { Advisor }\end{array}$ & $\mathrm{AC}$ & \\
\hline 4 & $\begin{array}{l}\text { Environment } \\
\text { Manager }\end{array}$ & LC & \\
\hline 5 & $\begin{array}{c}\text { Corporate } \\
\text { Environment } \\
\text { Manager } \\
\end{array}$ & GA & \\
\hline 6 & $\begin{array}{c}\text { Systems } \\
\text { Superintendent } \\
\text { (Quality \& } \\
\text { Environment) } \\
\end{array}$ & IW & \\
\hline 7 & $\begin{array}{l}\text { Risk, Safety and } \\
\text { Environmental } \\
\text { Manager }\end{array}$ & \multirow{2}{*}{$\begin{array}{c}\text { XX } \\
\text { Airport }\end{array}$} & \\
\hline 8 & $\begin{array}{l}\text { Facilities } \\
\text { Manager }\end{array}$ & & \\
\hline 9 & $\begin{array}{c}\text { National } \\
\text { Sustainability } \\
\text { Manager }\end{array}$ & BA & \\
\hline
\end{tabular}

The data analysis strategy entailed the construction of a 'story' that represented our account of the development of leadership capabilities. We analysed data in tandem with collection to take full advantage of the flexibility of the case research approach [49].

The data was organised and coded using the grounded theory techniques of open, axial, and selective coding [50]. More specifically, open coding was used to assign conceptual labels to data to create a pool of first-order themes (e.g. excerpts from interviews). The initial set of themes consisted of the elements of supply chain leadership practices. Axial coding was used to relate the first-order themes to several second-order themes [51]. The second-order themes were then abstracted into aggregate dimensions that emerged as a series of DCs to foster leadership and enable SSC.

\section{Case Background}

The infrastructure, construction, transportation, and logistics industry within Australia is experiencing significant challenges along their supply chain in relation to the sustainability of their operations. The
NSW Government spends approximately $\$ 10$ billion on purchasing, presenting opportunity to develop sustainable procurement capability [52]. To facilitate sustainable practices, the government established the Sustainability Advantage Platform. SA is a platform organised by the NSW Government Department of Planning, Industry and Environment (DPIE). This platform works in partnership with over 800 medium and large organisations to achieve sustainability. The online platform provides organisations with access to online training modules and access to a plethora of resources. Regarding sustainability ambitions, there are three primary targets SA is committed to, namely the use of Clean Energy and Net Zero Emissions, contribution to the United Nations Sustainable Development Goals and the creation of a Circular Economy within NSW. As the industry involvement with this platform is diverse, the focus of this case is on partners that operate within the infrastructure, construction, transport, and logistics industry.

SA strives to build strategic collaborative relationships between members to accelerate innovation and ultimately solve complex challenges. Members are required to pay an annual membership and receive support in the form of engagement with sustainability advisors, exclusive events, online resources, and e-newsletters for regular updates. Additionally, members are involved in the SA Recognition scheme. Here, based on their sustainability maturity, individuals are allocated to the member, bronze, silver, gold, or platinum tier. Each level of recognition is based on their time in the platform, as well as any significant or innovative sustainability projects. This scheme provides public recognition of an organisation's commitment to sustainable practices to both customers and competitors.

\section{Preliminary Analysis}

We subject empirical data collected to analysis strategy described earlier, to derive a set of findings on the dynamic capabilities SA members develop towards sustainability leadership. This led to the creation of a staged model of capability development for SSC leadership, as illustrated in Figure 1. The model spans across three incremental stages which involve three distinct capabilities based on Teece's [35] categorisation: Sensing, Seizing and Reconfiguring. The urge for organisations to develop these capabilities is highly motivated by external factors, specifically the realisation that SSC are pivotal to achieving sustainability ambitions.

In the following section, the notions of dynamic capabilities are examined through six key sub- 


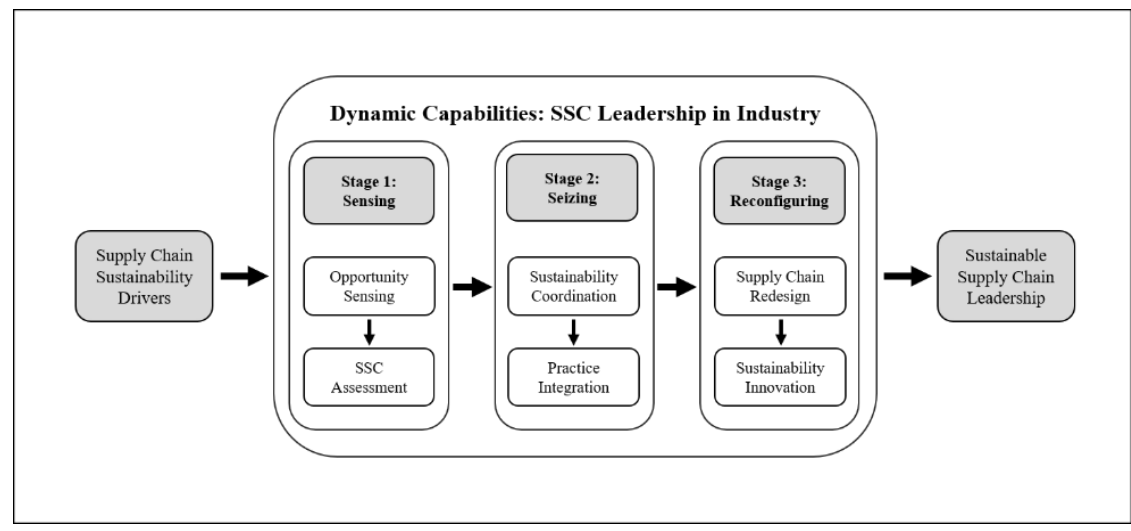

Figure 1. Staged Model of Capability Development for SSC Leadership

capabilities that demonstrate how participating firms enacted Teece's [35] sensing, seizing, and transforming capabilities. These sub-capabilities are critical in developing sustainability leadership, equipping organisations with the ability to exert influence, mobilise collective action and reimagine the environments in which they operate. The analysis identifies the processes by which organisations have the capacity to influence the sustainable operations of partners along their supply chain. The enactment of leadership for SSC is directly aligned with the creation of a circular economy, which is crucial in achieving the target of net zero emissions by 2030 .

Currently, sustainability across infrastructure, construction, transportation and logistics is extremely polarised, where firms' sustainability either drive their operations or are still in their infancy. Thus, these capabilities provide guidelines on how firms can bridge the sustainability chasm. Organisations whose sustainability practices are still in their infancy are unable to develop the leadership capacity to shape the practices of supply chain partners. As the case focuses on an ecosystem at an industry level, the model also unpacks the role of a governing body, the SA Platform, in assisting organisations develop these capabilities.

Considering the complexity of interactions in a supply chain network, various technologies have been identified as enablers to these capabilities. Based on the analysis, organisations that integrated technology were better able to develop capabilities that could help identify and address sustainability opportunities, as well as transform their resources and practices in response to external changes.

\subsection{Sensing: Sustainability Blueprint}

In the first stage of leadership development, there are two constructs by which sensing capabilities for sustainability is developed. Firstly, knowledge sharing within networks is an important aspect of leadership development. It enables shared learning, which uplifts the sustainable performance of the entire supply chain. Secondly, firms need to swiftly acquire information and recognise changes within their environment. Within the context of supply chains, firms must manage knowledge from external sources but more importantly, changes in the sustainability patterns of their partners. In the case of the SA ecosystem, firms needed to develop opportunity sensing and SSC assessment capabilities.

6.1.1. Opportunity Sensing. Opportunity sensing is the ability of firms to develop a conjecture about the evolution of sustainability, specifically identifying sustainability challenges and needs. To advance sustainability progress, it was imperative that participating firms were proactively discovering and creating opportunities to learn about their supply chain partners' practices. Thus, enabling firms to take on a more significant leadership role by identifying how to effectively harness their resources to improve overall supply chain sustainability performance.

"There's definitely more and more, greater and greater expectations that we have a leadership role in moving our suppliers into a more sustainable space." - Corporate Environment Manager, GA

By identifying supplier challenges, opportunity sensing allows firms to raise sustainability awareness and uplift overall knowledge across the supply chain.

6.1.2. SSC Assessment. To further enhance sensing capabilities, firms also required SSC measurement capabilities. SSC assessment is the ability of firms to acquire quantifiable real-time data on sustainability performance that allows the recognition of changes in consumption patterns. Such information creates intelligence, positioning firms to react to supply chain changes. These systems are often enabled by technology so firms can manage complex data sets and identify new opportunities through increased 
transparency. This capability is especially important for actioning strategies to achieve carbon neutrality by 2030. Firms must aim to improve not only their own practices, but also those of their suppliers. Assessment systems are critical for managing supply chains and are widely adopted by industry leaders.

"It's a data management system so every project every month has to upload their energy, water and waste data... every month it's uploaded into a system which can congregate all of that data and so it's a great way to be able to keep track of consumption." NSW Assistant Sustainability Manager, LL

Through the development of opportunity sensing and SSC assessment capabilities, firms are able to gather information on their supply chains to identify opportunities for performance improvement, while learning from the success of others. Firms are thus empowered to adopt a leadership role to shape their environment by having a shared understanding of sustainability maturity.

\subsection{Seizing: Harnessing SC Connectivity}

The second set of dynamic capabilities builds upon the sensing capabilities, which resulted in firms being able to identify and create opportunities for their supply chains. To progress the sustainability commitment of partners, firms must address identified opportunities and drive change. To capitalise on these opportunities, it is critical to pioneer the creation of new sustainability processes and practices. However, to achieve these outcomes two capabilities are required, which are sustainability coordination and practice integration.

6.2.1. Sustainability Coordination. Sustainability coordination requires a firm to be proactive in managing the sustainability practices of its network. They must seek to create a constructive and inclusive process with their supply network, based on the knowledge they acquired in the sensing phase. Within the context of the SA ecosystem, supply chain processes and relationships are inherently complex. Firms with limited resources and capacity were unable to prioritise sustainability initiatives but leading firms recognised the difficulty of progressing towards sustainability targets without active participation from all supply chain members.

"A lot of the time we wouldn't achieve the outcomes that we're getting, and in the embodied carbon space there's no way we're going to achieve net zero by 2050, if we're not working with the supply chain and bringing the supply chain along." - NSW Assistant Sustainability Manager, LL
Leading firms needed to adopt an orchestrating role across their entire supply chain to provide oversight and ensure alignment with overarching goals. To support the required coordination, the SA Platform played a critical role in enabling this coordination, providing members with access to an inventory of sustainable materials from various subcontractors, which could be embedded throughout all projects.

"Key to that is engagement with subcontractors to look at how you can take sort of a target and really push it to the max. You have to make sure that the targets are in the contracts to begin with I think that's really important... to kind of get the most out of the supply chain." - NSW Assistant Sustainability Manager, $L L$

On the other hand, the supply chain also encapsulates the firms' customers, whereby firms are required to respond to various demands. Sustainability coordination requires the creation of a shared agenda and language for effective collaboration.

"A lot of the drive from our side of things is because our customers are asking us, are we involved in larger contracts. A lot of the big contracts like LL, and those companies ask you if you're involved in those sort of programs. And the community as well, the community's got an expectation that as a corporate organization, that you're involved in these sort of things." - Corporate Environment Manager, GA

6.2.2. Practice Integration. The second capability required for seizing is practice integration, which involves operationalising the various strengths and weaknesses of each member along the supply chain to create synergies. One component of integrating sustainability practices is the development of a collective commitment to sustainability targets, where progress can be monitored through the digitisation of workflows. For instance, within the case many firms had internal green standards or broader alignment to specific SDGs and the CN30 agreement, with firms using online tools to provide a consistent way to benchmark development. Furthermore, leading firms needed to leverage the unique capabilities of all suppliers, regardless of the state of their sustainability practices, to ensure optimal performance across the entire network. By doing so, they were able to engage in resource sharing to uplift overall capabilities. Firms must also seek to shape the practices of those they interact with by educating them about sustainability and increasing connectivity.

"LL has a commitment to sustainability and that's a really critical lever to be able to pull when you're working with teams... we work with small suppliers, we don't want to end up in this world where we're only 
working with big suppliers. - NSW Assistant Sustainability Manager, LL

Members have been able to effectively integrate various supplier practices through collaborating with SA to digitise workflows and movements throughout the supply chain. Such digitisation provides involved members with visibility over the development process, ensuring that firms are continuously striving to meet sustainability targets.

"Through our digital workflow the theory is that we will have checks and balances and gateways and that sort of thing which will allow different stakeholders to sign off on activities to ensure that sustainability is being met" - National Sustainability Manager, $B A$

\subsection{Reconfiguring: Unlocking Sustainability Innovation}

Finally, once firms have aligned sustainability goals and engage in participatory relationships with their supply chain through integration via online channels, firms must transform and continuously restructure their network and resources. This would allow them to quickly adapt to any changes relating to sustainability. To effectively reconfigure sustainable resources, firms must engage in the redesign of their supply chain and sustainability innovation.

6.3.1. Supply Chain Redesign. Supply chain redesign is the process of identifying the various materials flows and recombining them to address opportunities for more sustainable practices. It involves the use of key data sources, and technology systems, to be able to dynamically reallocate resources. Within the case, many firms had implemented environmental management systems that quantified operational footprint. However, such systems were mainly used to manage compliance and provide visibility over consumption. The successful reconfiguration of resources required a more proactive approach, where firms actively adjusted supply chain inputs to ensure optimal progress towards goals was achieved.

"I think the key to that is having someone whose role it is to take that data and do something with it. You can create like reports every month, but if no one's actually looking at that to then either tune systems or work with occupants" - Risk, Safety and Environmental Manager, XX Airport

For instance, data from life cycle assessments were displayed on a dashboard in a reporting software. The purpose was to manage the performance of fuel, electricity, and recycling amongst other sustainability metrics. However, firms have also identified the opportunity to extend the usability of the data beyond reporting and instead use it to continuously reengineer systems in accordance with changing environmental needs.

"I'm using it to inform the business leadership, the owners of the business, how we're tracking against our targets... In the future, we can leverage this to dig into what are our major waste streams, and are there opportunities for us to actually separate out that waste and divert it in a more efficient manner?" - National Sustainability Manager, BA

6.3.2. Sustainability Innovation. Sustainability innovation is a core pillar in enacting the reconfiguration of sustainability resources. A critical aspect of this is cross industry collaboration for coinnovation to ensure firms are continuously seeking opportunities to develop their sustainability, and subsequently, their leadership capacities. Coinnovation needs to occur with partners who have the resources to invest and influence practices across industry. Thus, the SA Platform plays a crucial role in stimulating innovation potential and equipping firms with the resources to assume a leading role across their supply chains. This is enabled through the various online forums and training modules that are distributed through their online platform. Many partnered firms have recognised the importance of SA in galvanising a platform which firms and their subcontractors and suppliers can subscribe to. However, many participating firms are yet to leverage the capabilities of this platform to its full extent due to several constraints, such as a lack of time and prioritisation.

\section{Discussion and Conclusion}

With an increasing focus on sustainable development, many firms are recognising the need for collective action. However, there is a lack of understanding of how to develop the capability to enable this coordination. The development of these six sub-capabilities for sensing, seizing and reconfiguring, positions firms as sustainability leaders within the industry. It provides them with the capacity to not only exceed their sustainability targets, but to also shape the practices of those in its surrounding networks and uplift the overall performance across their industry. While some firms are successful in actively engaging their supply chain, there are still significant opportunities to transform practices and this must be enabled through collaboration with a broader set of partners, such as the SA Program. The platform provided member organisations with access to both information and resources to support sustainability progress, providing a mechanism for the distribution of knowledge from leaders to the member network. 
This access to information through digitised workflows provided greater connectivity with practices along supply chains, ensuring progress towards mutual sustainability targets was made. The platform also enhanced supply chain coordination through the provision of an online inventory that offered a catalogue of pre-vetted sustainable materials that firms previously did not have access to.

In terms of research implications, this study addresses the lack of empirical research on the development of leadership capabilities for SSC. This study extends the corpus of literature by examining how sustainability leaders built capabilities to support progress within a sustainability-driven ecosystem. This study presents a staged model of capability development for SSC leadership, which is derived through the application of dynamic capabilities. It also highlights the enabling role platforms can have in supporting leadership development.

In terms of practical implications, the staged model provides a reference for organisations who are collaborating for a circular economy. The various technologies identified with the six capabilities can be adapted. Additionally, the model serves to inform the government on how they can facilitate action towards the SDGs and carbon neutral by 2030 agreement.

Despite the present research implications, further research is required to enhance the generalizability of the findings. The study can be extended by conducting investigations of organisations across various industries, and analysing practices that are distributed in terms of sustainability maturity. Research within these areas will unearth different sustainability challenges that organisations are experiencing and new constructs by which such challenges are addressed. Further research will provide a more comprehensive discussion on the role that government platforms have in mediating institutional forces that inhibit leadership development, as well as opportunities to further facilitate

\section{Acknowledgements}

We acknowledge the kind and ongoing support of the NSW Government Sustainability Advantage Program in this project. This project is funded by research agreement RG202297.

\section{References}

[1] United Nations 2019a, Community Development.

[2] United Nations 2019b, Transforming Our World: The 2030 Agenda for Sustainable Development.
[3] Kumar, D. \& Rahman, Z. 2016, "Buyer supplier relationship and supply chain sustainability: empirical study of Indian automobile industry", Journal of Cleaner Production, vol. 131, pp. 836-848.

[4] Meqdadi, O.A., Johnsen, T.E. \& Johnsen, R.E. 2019, "Power and Diffusion of Sustainability in Supply Networks: Findings from Four In-Depth Case Studies", Journal of Business Ethics, vol. 159, no. 4

[5] Sharif, A.M. \& Irani, Z. 2012, "Supply chain leadership", International journal of production economics, vol. 140, no. 1, pp. 57-68.

[6] Kingo, L. \& Murphy, C. 2020, 12 June-last update, How to build sustainable business leadership in a postCOVID world.

[7] Clifford, D.C., Esper, T. \& Mollenkopf, D. 2009, "Leveraging closed-loop orientation and leadership for environmental sustainability", Supply Chain Management: An International Journal, vol. 14, no. 2

[8] Silvestre, B.S. 2015, "A hard nut to crack! Implementing supply chain sustainability in an emerging economy", Journal of Cleaner Production, vol. 96

[9] Han, Z. \& Huo, B. 2020, "The impact of green supply chain integration on sustainable performance", Industrial Management \& Data Systems, vol. 120, no. 4, pp. 657-674.

[10] Lisi, W., Zhu, R. \& Yuan, C. 2020, "Embracing green innovation via green supply chain learning: The moderating role of green technology turbulence", Sustainable Development, vol. 28, no. 1

[11] van Bommel, Harrie. W. M 2011, "A conceptual framework for analyzing sustainability strategies in industrial supply networks from an innovation perspective", Journal of Cleaner Production, vol. 19

[12] Hsu, C., Kuo, T., Chen, S. \& Hu, A.H. 2013, "Using DEMATEL to develop a carbon management model of supplier selection in green supply chain management", Journal of Cleaner Production, vol. 56,

[13] Tan, B., Pan, S.L. \& Zuo, M. 2015, "Harnessing collective IT resources for sustainability: Insights from the green leadership strategy of China mobile", Journal of the Association for Information Science and Technology, vol. 66, no. 4, pp. 818-838.

[14] Mokhtar, A.R.M., Genovese, A., Brint, A. \& Kumar, N. 2019, "Supply chain leadership: A systematic literature review and a research agenda", International Journal of Production Economics, vol. 216, pp. 255-273.

[15] Evangelista, P, Santoro, L \& Thomas, A 2018, 'Environmental Sustainability in Third-Party Logistics Service Providers: A Systematic Literature Review from 2000-2016', vol. 10, no. 5, p. 1627.

[16] Touboulic, A., Chicksand, D. \& Walker, H. 2014, "Managing Imbalanced Supply Chain Relationships for Sustainability: A Power Perspective", Decision Sciences, vol. 45, no. 4, pp. 577-619.

[17] Vial, G. 2019, Understanding digital transformation: A review and a research agenda, The journal of strategic information systems, vol. 28, no. 2, pp. 118-44.

[18] Dubey, R., Gunasekaran, A. \& Samar Ali, S. 2015, "Exploring the relationship between leadership, operational practices, institutional pressures and environmental performance: A framework for green 
supply chain", International Journal of Production Economics, vol. 160, pp. 120-132.

[19] United Nations Global Compact 2019, UN Global Compact-Accenture Strategy 2019 CEO Study - The Decade to Deliver: A Call to Business Action.

[20] Chen, Y. \& Chang, C. 2013, "The Determinants of Green Product Development Performance: Green Dynamic Capabilities, Green Transformational Leadership, and Green Creativity", Journal of Business Ethics, vol. 116, no. 1, pp. 107-119.

[21] Mittal, S. \& Dhar, R.L. 2016, "Effect of green transformational leadership on green creativity: A study of tourist hotels", Tourism Management, vol. 57

[22] Singh, S.K., Giudice, M.D., Chierici, R. \& Graziano, D. 2020, "Green innovation and environmental performance: The role of green transformational leadership and green human resource management", Technological Forecasting \& Social Change, vol. 150, pp. 119762.

[23] Eisenmann, T., Parker, G. \& Van Alstyne, M. 2011, Platform envelopment, Strategic management journal, vol. 32, no. 12, pp. 1270-85.

[24] Hagiu, A. \& Hałaburda, H. 2014, Information and twosided platform profits, International journal of industrial organization, vol. 34, pp. 25-35.

[25] Gawer, A. \& Cusumano, M.A. 2008, How companies become platform leaders, MIT Sloan management review, vol. 49 , no. 2 , p. 28.

[26] Hagel, J. \& Davison, L. 2008, Shaping strategy in a world of constant disruption, vol. 86, no. 10, pp. 80-9.

[27] Tan, F.T.C., Pan, S.L. \& Zuo, M. 2018, Realising platform operational agility through information technology-enabled capabilities: A resourceinterdependence perspective, Information systems journal (Oxford, England), vol. 29, no. 3, pp. 582-608.

[28] Gandal, N. 1995, Competing Compatibility Standards and Network Externalities in the PC Software Market, The review of economics and statistics, vol. 77, no. 4

[29]Sedera, D., Lokuge, S., Grover, V., Sarker, Suprateek \& Sarker, Saonee 2016, Innovating with enterprise systems and digital platforms: A contingent resource-based theory view, Information \& management, vol. 53, no. 3

[30] Teece, D.J., Pisano, G. \& Shuen, A. 1997, "Dynamic Capabilities and Strategic Management", Strategic Management Journal, vol. 18, no. 7, pp. 509-533.

[31] Barney, J. 1991, "Firm Resources and Sustained Competitive Advantage", Journal of Management.

[32] D'Aveni, R.A. 1994, Hypercompetition, Free Pr, New York.

[33] Eisenhardt, K.M. \& Martin, J.A. 2000, "Dynamic Capabilities: What Are They?", Strategic Management Journal, vol. 21, no. 10/11, pp. 1105-1121.

[34] Hill, C.W.L. \& Rothaermel, F.T. 2003, "The Performance of Incumbent Firms in the Face of Radical Technological Innovation", The Academy of Management Review, vol. 28, no. 2, pp. 257-274.

[35] Teece, D.J. 2007, "Explicating Dynamic Capabilities: The Nature and Microfoundations of (Sustainable) Enterprise Performance", Strategic Management Journal, vol. 28, no. 13, pp. 1319-1350.
[36] Mousavi, S., Bossink, B. \& van Vliet, M. 2018, "Dynamic capabilities and organizational routines for managing innovation towards sustainability", Journal of Cleaner Production, vol. 203, pp. 224-239.

[37] Dangelico, R.M., Pontrandolfo, P. \& Pujari, D. 2013, "Developing Sustainable New Products in the Textile and Upholstered Furniture Industries: Role of External Integrative Capabilities", The Journal of product innovation management, vol. 30, no. 4, pp. 642-658.

[38] Beske, P. 2012, "Dynamic capabilities and sustainable supply chain management", International Journal of Physical Distribution \& Logistics Management, vol. 42

[39] Reuter, C., Foerstl, K., Hartmann, E. \& Blome, C. 2010, "Sustainable Global Supplier Management: The Role of Dynamic Capabilities in Achieving Competitive Advantage", Journal of Supply Chain Management, vol. 46, no. 2, pp. 45-63.

[40] Hart, S.L. \& Dowell, G. 2011, "A natural-resourcebased view of the firm: fifteen years after", Journal of Management, vol. 37, no. 5, pp. 1464.

[41] Glavas, A. \& Mish, J. 2015, "Resources and capabilities of triple bottom line firms", Journal of business ethics, vol. 127, no. 3, pp. 623-642.

[42] Silvestre, B.S. 2015, "Sustainable supply chain management in emerging economies: Environmental turbulence, institutional voids and sustainability trajectories", International Journal of Production Economics, vol. 167, pp. 156-169.

[43] Gosling, J., Jia, F., Gong, Y. \& Brown, S. 2016, "The role of supply chain leadership in the learning of sustainable practice: toward an integrated framework", Journal of Cleaner Production, vol. 137,

[44] Walsham, G. 1995, "Interpretive case studies in IS research: nature and method", European Journal of Information Systems, vol. 4, no. 2, pp. 74-81.

[45] Gephart, R.P. 2004, "Qualitative Research and the Academy of Management Journal", Academy of Management journal, vol. 47, no. 4, pp. 454-462.

[46] Kleins, H.K. \& Myers, M.D. 1999, "A Set of Principles for Conducting and Evaluating Interpretive Field Studies in Information Systems", MIS Quarterly, vol. 23, no. 1

[47] van der Vorst, Jack G. A. J \& Beulens, A.J.M. 2002, "Identifying sources of uncertainty to generate supply chain redesign strategies", International Journal of Physical Distribution \& Logistics Management, vol. 32, no. 6, pp. 409-430.

[48] Tricoire, J. , Here's why green manufacturing is crucial for a low-carbon future.

[49] Eisenhardt, K.M. 1989, "Building Theories from Case Study Research", The Academy of Management review, vol. 14, no. 4, pp. 532-550.

[50] Strauss, A.L. \& Corbin, J.M. 1998, Basics of qualitative research, 2nd ed. edn, Sage Publications, Thousand Oaks.

[51] Gioia, D.A., Corley, K.G. \& Hamilton, A.L. 2013, "Seeking Qualitative Rigor in Inductive Research", Organizational Research Methods, vol. 16, no. 1 , pp. 15-31.

[52] Local Government, N. 2017, Sustainable Procurement Guide for Local Government in NSW. 